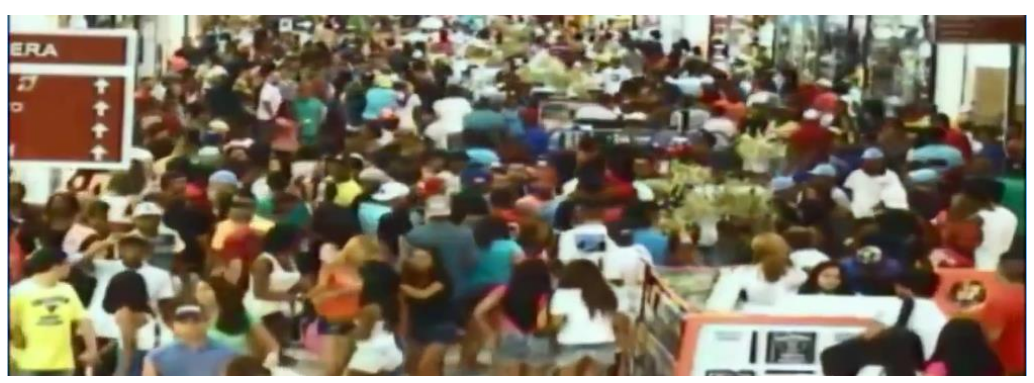

\title{
Consumo, espaço e identificação: o sujeito rolêzeiro na rede de sentidos.
}

Consumption, space and identification: the subject rolêzeiro in the network of senses.

\author{
Guilherme Carrozza ${ }^{1}$ \\ Carina Carnevalli Alvarenga ${ }^{2}$
}

\begin{abstract}
Resumo:
$\mathrm{O}$ viver em sociedade no mundo contemporâneo traz questões que tocam nos modos como o sujeito lida com a ideologia, pensada como materialmente ligada ao inconsciente. Isso significa dizer que o sujeito se constitui pelos discursos que circulam socialmente e produzem lugares de identificação. Uma das entradas onde é possível observar esse funcionamento é o corpo do sujeito que, de acordo com Orlandi (2012), é tomado como materialidade significativa. Trazemos para a reflexão um tipo específico de manifestação pública, conhecido como rolêzinho, tendo como foco de observação o corpo do sujeito em movimento no espaço público, relacionando-o a uma lógica de funcionamento capitalista, na qual as relações de consumo são determinantes. Pretendemos levar às consequências as reflexões acerca da relação dos sujeitos com seus corpos inseridos em espaços determinados de circulação, onde a organização desponta como naturalmente necessária. Palavras-chave: Sujeito, Corpo, Espaço, Consumo, Marca, Rolêzinho
\end{abstract}

\begin{abstract}
:
By living in society in the contemporary world, we demand questions about how the subject deals with the ideology, what is, from our perspective, materially connected to the unconscious. This means that the subject is constituted as such by the discourses those circulate and produce places of identification. One of the inputs where it is possible to observe that this function, is the subject body that, according to Orlandi (2012), is taken as significant materiality. We bring to reflect a specific type of public demonstration, known as "rolêzinho", with the observation focus the body of the subject moving in public space, linking it to a capitalist logic of operation, in which consumer relations are crucial. We intend to take the consequences of the reflections on the relationship of individuals with their bodies placed in certain areas of circulation, where the organization stands out as naturally necessary.
\end{abstract}

Keywords: Subject, Body, Space, Consumption, Brand, Rolêzinho

\footnotetext{
1 Professor e pesquisador do Programa de Pós-Graduação em Ciências da Linguagem da Univás Universidade do Vale do Sapucaí. Coordenador do Projeto de Pesquisa Sujeito, Espaço, Corpo e Sentido, em parceria com a Faculdade de Comunicação da Universidade de Juiz de Fora. E-mail: guilhermecarrozza@uol.com.br. Endereço: Av. Prefeito Tuany Toledo, 470 - Bairro Fátima, Pouso Alegre, MG - CEP 37550-000

${ }^{2}$ Bolsista Probic Fapemig em 2015, aluna de graduação do curso de Publicidade e Propaganda da Univás - Universidade do Vale do Sapucaí. E-mail: carinacalvarenga@ hotmail.com. Endereço: Av. Prefeito Tuany Toledo, 470 - Bairro Fátima, Pouso Alegre, MG - CEP 37550-000
} 
O homem, como ser social, histórico e simbólico, é instado constantemente a lidar com certos modos de relações que colocam em jogo alguns sentidos já cristalizados, postos em circulação na sociedade. Ao serem desestabilizados, tais sentidos apontam para novas práticas e modos de como esse sujeito vai, então, se relacionar com os espaços que habita e, consequentemente, com os usuários desses espaços.

Pensar o espaço discursivamente significa ir além do seu aspecto físico e encarálo como aquilo que abriga o "físico-e-o-social". Nesse sentido, espaço, para a Análise de Discurso que praticamos é, sobretudo, lugar de relações.

Procuramos, tendo essa noção de espaço como foco, analisar um acontecimento relativamente recente no Brasil, que no nosso entendimento, levantou questões sobre o funcionamento do espaço nas grandes cidades. Tratam-se dos rolêzinhos, que foram encontros em shopping centers marcados pela internet por adolescentes e que ocorreram no final de 2013 e início de 2014, geralmente convocados por cantores de funk ou os chamados "famosinhos da internet", desse estilo musical nas ruas da capital paulista ${ }^{4}$.

A partir desses encontros, incomodados com os jovens que se reuniram em suas dependências cantando refrãos de funk ostentação ${ }^{5}$ nos corredores, as direções de alguns shoppings da capital paulista tiveram o respaldo de decisões judiciais para fazerem a triagem de clientes. Além disso, a repressão policial aos participantes também gerou grande repercussão nos meios de comunicação.

Algumas das questões que se levantam diante desse fato já são conhecidas dos que se ocupam com temas relacionados à cidade, como a relação entre o público e o privado e a questão da interdição. Outras, porém, dentro de nossa linha de pensamento, se

\footnotetext{
${ }^{3}$ A denominação se deve, fundamentalmente, à quantidade de seguidores e amigos virtuais que tais sujeitos possuem nas redes sociais. Trata-se, no nosso entendimento, de algo que tem estreita relação com a visibilidade propiciada pelas novas tecnologias das relações

${ }^{4}$ Embora o foco desse estudo tenha se dirigido aos comentários que se produziram àquela época sobre os rolêzinhos nos meios de comunicação, é importante destacar que esses movimentos, após toda a celeuma que causaram, continuaram acontecendo em outros espaços da cidade que não os shoppings, ocorrendo até hoje em locais públicos, como ruas, parques e praças.

${ }^{5}$ Segundo o site entretenimento.r7.com (acessado em 15 de abril de 2016), há alguns tipos de funk, classificados em função, principalmente, do conteúdo das letras das músicas e de suas batidas: o funk carioca, o funk rasteirinha, o funk proibidão, o funk melody e o funk ostentação, também conhecido como funk paulista. Este último, que possui relação direta com nosso tema, tem como objeto o consumo. O termo "ostentação" ressalta o "ter" e o "consumir" e merecerá de nós mais atenção à frente.
} 
mostram mais inusitadas, na medida em que fazemos entrar a questão do corpo do sujeito que circula nesse espaço.

Diante disso, tivemos como proposta para esta reflexão, abordar três pontos que julgamos expoentes nesta relação e que colocam em evidência certos funcionamentos que se estabelecem pelo modo como a sociedade pratica o jogo das relações sociais: o primeiro deles diz respeito à ordem do espaço e o imaginário de organização como aquilo que rege o modo como os corpos se movimentam neste espaço; o segundo se refere a esse corpo revestido, neste caso por marcas de consumo, e como isso funciona no processo de identificação dos sujeitos; e, por fim, procuramos também compreender como o corpo circula entre o virtual e o real ${ }^{6}$, uma vez que as relações são hoje, em grande medida, mediadas pelas tecnologias.

Da mesma forma que tomamos a noção de espaço discursivamente, é importante que se saliente que também o corpo aqui é pensado nesta dimensão, como materialidade significativa (ORLANDI, 2012). Assim, para nós, o corpo se configura como parte da materialidade do sujeito. Isso significa dizer, a partir de Orlandi (2012), que o corpo não pode ser tomado como corpo empírico, "mas como corpo em sua materialidade significativa enquanto corpo de um sujeito. " (Idem, p. 85). Nessa linha de pensamento, a autora propõe refletir sobre a relação entre corpo e ideologia, partindo do princípio de que "o corpo do sujeito está atado ao corpo da cidade, ao corpo social." (Idem, p. 86). Ou seja, há que se levar em conta que não se trata de qualquer forma de corpo, mas do corpo que materializa uma determinada formação social, numa determinada conjuntura, e que se textualiza dentro da narratividade urbana.

O que estamos querendo dizer com isso é que não se pode tomar tais sujeitos como abstrações categorizantes, como meros representantes de uma classe da periferia ou então como pessoas sem poder aquisitivo para frequentar locais ditos de elite, mas pensá-los em sua materialidade significante, na qual o corpo se apresenta como fundante. Nesse sentido, o modo como o sujeito se movimenta socialmente com seu corpo produz seus efeitos. Dentro disso, é possível levantar um questionamento sobre os modos de organização do espaço urbano e a partir de que se pode considerar um aglomerado de pessoas (tanto em quantidade, quanto em postura) como aquilo que vem desestabilizar essa organização, produzindo reações diversas nos mais diferentes lugares sociais.

\footnotetext{
${ }^{6}$ A questão, aqui, na verdade, se coloca na relação entre espaço digital e espaço físico, considerando-se, nessa relação, a materialidade do corpo que circula no digital e a do corpo que circula no plano físico.
} 
Vamos partir de uma afirmação do presidente da Allshop - Associação dos Lojistas de Shopping Centers - Sr. Nabil Sahyon, em entrevista a um documentário da TV Folha, produzido à época dos acontecimentos. Diz ele:

\begin{abstract}
Sequência 1:
"O rolêzinho é a busca por um espaço que eles possam ter, que eles não têm hoje, que é da responsabilidade do Estado, de responsabilidade da prefeitura e é o que a gente agora está procurando pleitear: um espaço onde eles possam extravasar suas alegrias e a gente poder manter os shoppings onde todos eles poderão frequentar, de uma forma individual como vem acontecendo, de uma forma de três, quatro pessoas entrando juntas, mas não mil, mil e quinhentas, duas mil pessoas".
\end{abstract}

Orlandi (2001) muito bem já colocou que “a quantidade é um elemento estruturante das relações sociais quando consideramos a cidade como um lugar simbólico correspondente a um espaço real concreto" (idem, p. 190). E continua:

Há uma demanda política e simbólica da cidade que passa pela quantidade funcionando em um espaço historicizado: esta ancoragem simbólico-política que é a quantidade espera por metaforização em gestos de interpretação próprios à cidade em suas diferentes formas de significar. No entanto em um espaço urbano, não há espaço vazio (espaços disponíveis): há o muito cheio (o excesso) do discurso sobre o urbano, uma saturação dos sentidos públicos que desemboca na desorganização, já que não há espaço para a incompletude. Não há sentidos possíveis que poderiam romper o espaço simbólico já significado.

Para a autora, a violência decorre no modo como essa quantidade se metaforiza, pois apaga a distinção entre o socius e o hostis, colocando "o outro, lançado na multidão desconhecida, como o inimigo" (idem, p. 190).

Diríamos, ainda, corroborando com o pensamento de Orlandi que, neste caso específico, não só a quantidade de pessoas incomoda e revolve os sentidos já estabilizados do shopping, mas também o modo como circularam todos, em conjunto, num mesmo movimento. Ora, não é difícil observar um shopping próximo a datas comerciais, como Natal por exemplo, repleto de pessoas fazendo suas compras. Mas é justamente o fato de se movimentarem de modo "organizadamente desorganizado", cada um em uma direção, ou em pequenos grupos, que representa a ordem imaginária do shopping. São indivíduos, cada um com seu propósito, fazendo suas compras. Diferente de um grupo, reunido em torno de um mesmo propósito, caminhando na mesma direção, formando uma massa de pessoas que, não só pela quantidade, mas também pelo corpo em movimento, causam 
estranhamento (figura 1). E aqui se estabelece a primeira diferença entre "estar em um shopping" e "estar em um rolêzinho": tem a ver, sobretudo, com a relação indivíduo/sujeito, na medida em que distinguimos um gesto individual de um gesto coletivo - o indivíduo e o grupo.
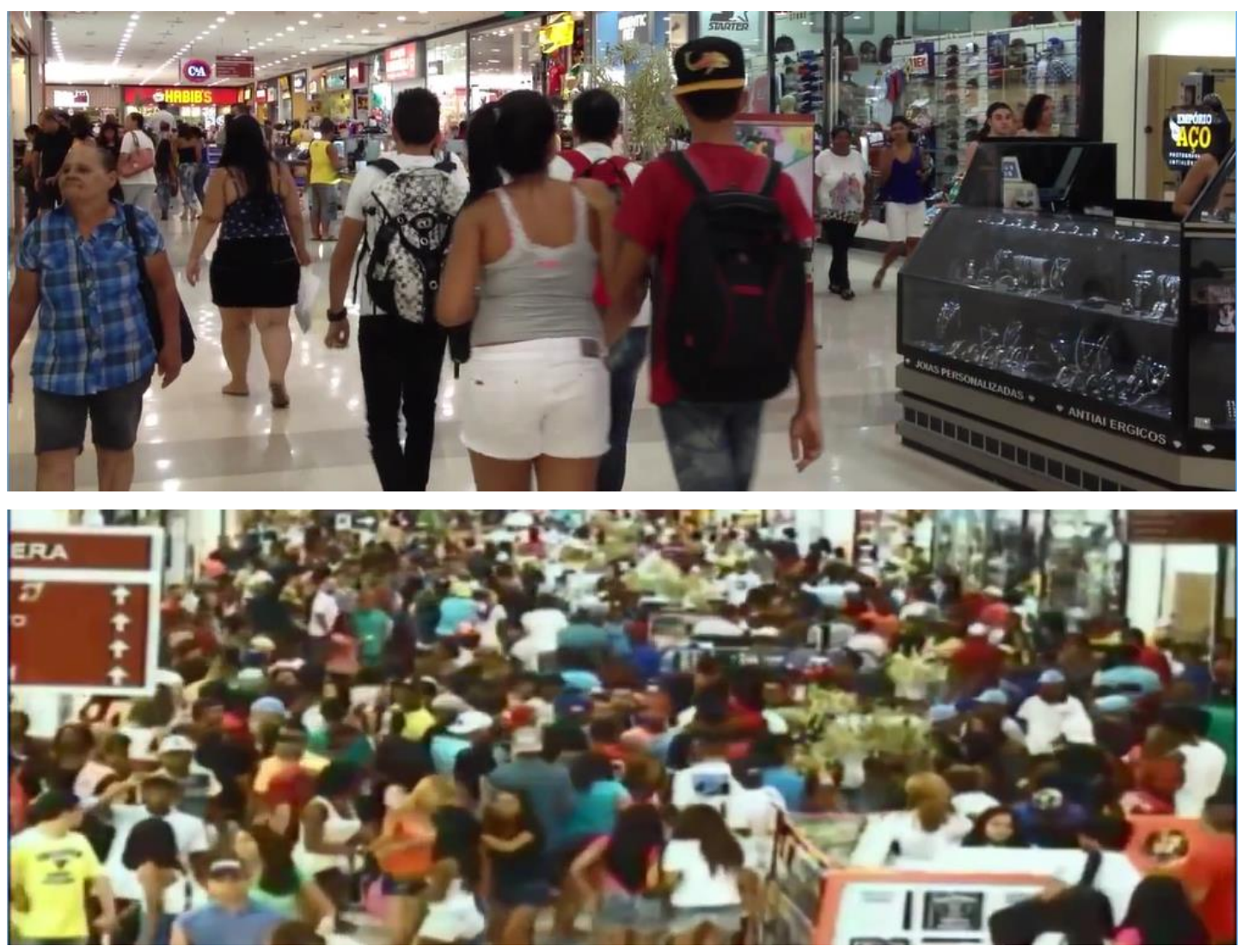

Figura 1 - Comparação entre o movimento de um shopping considerado dentro dos padrões normais e outro, gravado por câmeras de segurança em um dia de evento de rolêzinho.

É disso que falamos quando afirmamos que o corpo não é representação e nem forma de expressão. Corpo é corpo-e-palavra, corpo-e-gesto, corpo-e-movimento. O corpo, para a Análise de Discurso, é matéria: form(a)tada ao/pelo corpo social. E esse corpo faz sujeito. Está submetido a uma ordem que o significa como sujeito que está, sobretudo, imerso no processo que constrói a narratividade urbana.

Considerar a narratividade urbana significa também levar em conta os modos de construção discursiva da realidade, a partir dos acontecimentos que, de uma forma ou de outra, ganham visibilidade nos meios de comunicação de massa e em outros espaços de circulação de informação, como as redes sociais. Além disso, partimos da suposição de que falar do urbano significa, também, falar das relações de consumo que se estabeleceram a partir da constituição da forma sujeito histórica contemporânea e que afetam sobremaneira os modos como os sujeitos circulam no espaço citadino. Nessa 
perspectiva, a maneira como o sujeito se constitui e se move (com seu corpo) têm a ver com as determinações históricas e ideológicas que vieram se configurando através do próprio funcionamento social no qual, no nosso ponto de vista, estão arraigadas as relações de consumo. Isso abre caminho para fenômenos como este, do funk ostentação, do vestir-se de determinado modo para afirmar-se como rolêzeiro e, principalmente, dos rolêzinhos acontecerem em shopping centers, símbolos por excelência do mercado e do consumo.

Em um dos materiais analisados, uma garota frequentadora de rolêzinho assim se refere aos garotos:

\section{Sequência 2:}

"Tem que tá com uma bermuda branca, Nike Shox, uma camiseta da Hollister ou da Aeropostale, um Juliette e um boné. Tá perfeito, esse é o gato do rolê, que chama atenção.

Em outra reportagem analisada, um rolêzeiro diz:

\section{Sequência 3:}

"É importante andar na moda porque é uma referência do que você é."

Há ainda a afirmação de Renato Meirelles, Presidente do Instituto de Pesquisa Data Popular, em um documentário da TV Folha:

\section{Sequência 4:}

"A marca, muitas vezes, serve para celebrar a melhora de qualidade de vida."

Vamos relembrar mais uma vez Orlandi (2006, p. 25) quando, citando Kaës (2005), salienta que a vestimenta é uma pele do grupo. E continua:

Fora dessa pele e das identificações que ela organiza não há salvação. Sem esta pele, este envelope, não há identificação possível, no duplo sentido do termo [...] não há referência identificadora, signo identitário, nem impressão, marca. Há uma outra função, delimitativa, da pele e da vestimenta: a figuração de um corpo-grupo.

Vale considerar, a partir daí, como há, nesse sentido, a abertura para a entrada das marcas de consumo, estampadas nas roupas desses sujeitos, como lugares de identificação, nos quais esses rolêzeiros se inscrevem como participantes de um tipo específico de grupo. Nesse sentido, estar (re)vestido de marcas de consumo é afirmar-se não apenas como alguém do grupo, mas alguém que "celebra" para o grupo uma 
imaginária posição social. O sentido de ter desliza para o ser. Vestir-se é, sobretudo, identificar-se como sendo rolêzeiro. É eficaz esse funcionamento do imaginário, que coloca em evidência o próprio sentido de ostentação.

Orlandi (1994) chama a atenção para a especificidade que a noção de imaginário adquire dentro da Análise de Discurso salientando que mesmo não havendo relação direta entre linguagem e mundo, essa relação funciona como se fosse, por causa, justamente, do imaginário. Para Orlandi (idem, p. 57)

...a dimensão imaginária de um discurso é sua capacidade para a remissão de forma direta à realidade. Daí seu efeito de evidência, sua ilusão referencial. Por outro lado, a transformação do signo em imagem resulta justamente da perda do seu significado, do seu apagamento enquanto unidade cultural ou histórica, o que produz sua "transparência". [...] Essa relação com a história mostra a eficácia do imaginário, capaz de determinar transformações nas relações sociais e de constituir práticas.

Nesse sentido é que podemos dizer que nossa realidade se constrói pelo imaginário que se estabelece nas relações sociais e que, por força da ideologia ${ }^{7}$, tem efeito de real, trazendo a ilusão de que as coisas são como são. Aliás, é importante dizer que só há sentido na ostentação porque há imaginário. A ostentação não está no possuir o objeto em si, mas na posse de um imaginário que o sujeito pratica no seu gesto de consumo, quando ao adquirir e se colocar como usuário de determinada marca, se inscreve na rede de memórias que ela própria faz vir à tona.

Partindo de Pêcheux (in ACHARD, 1999, p.50) que nos fala de uma "memória social inscrita em práticas", pensamos na memória que funciona pelo esquecimento e que se constitui como materialidade na estruturação do discursivo (ACHARD, 1999). A memória discursiva que representa a base para o legível, o interpretável.

Orlandi (2013), a partir da noção de arquivo colocada por Pêcheux (1997) faz a distinção entre

... a memória discursiva (interdiscurso, constituída pelo esquecimento), a memória metálica (das máquinas) e a memória de arquivo, sendo esta a memória institucional, a que não esquece e alimenta a ilusão da "literalidade", acentuando a ilusão de transparência da linguagem, sustentada pelas instituições, lugares por onde circula o discurso documental e que servem a sua manutenção e estabilização.

Assim, numa articulação do simbólico com o político, a "memória de arquivo" é aquela disponibilizada ao sujeito para que funcione como retomadas de sentido das coisas

\footnotetext{
${ }^{7}$ A noção de ideologia tal como a concebemos na Análise de Discurso que praticamos, se coloca como basilar ao próprio processo de produção de sentido.
} 
com as quais ele se relaciona no mundo. Trata-se, nesse aspecto, de uma memória representada, localizável. Esse funcionamento estabelece, por assim dizer, práticas de memória que direcionam o modo como o sujeito constrói sua referência de mundo. $\mathrm{Na}$ relação com as marcas de consumo, é o trabalho de administração dos sentidos, através das estratégias publicitárias, que faz com que uma rede de memória esteja sempre lá, disponível, para que o sujeito nela se inscreva na medida em que se coloca como consumidor de determinada marca. Assim, a marca funciona, sobretudo, como metáfora da existência social do sujeito. Vestir o corpo com ela é projetar-se como sujeito e se significar a partir da sua pele social.

Resta ainda chamar atenção para outro ponto que, ao considerar o corpo como vimos fazendo, parece também trazer à tona o modo como esse sujeito pragmático tem na coincidência entre sujeito e corpo seu ponto nodal.

Quando pensamos nos sujeitos rolêzeiros e, principalmente, nos "famosinhos da internet" como colocamos anteriormente, pensamos nas redes sociais como espaços de relações, que são colocados por muitos como espaços de relações virtuais. Esse, aliás, parece ser um equívoco que hoje funciona pela história do uso do próprio termo "virtual", como aquilo que se separa de forma estanque do que é real, como se fossem dois espaços distintos de acontecimentos distintos. Baldini (2011) alerta para o fato de que cair numa oposição simplista entre o mundo real e o mundo virtual não nos deixa ver que se trata, na verdade, de uma nova relação dos sujeitos consigo mesmos e com os outros. Estamos dizendo com isso que não se tratam, então, de formas opostas de relação, mas sim de outras formas simplesmente. Mas o corpo desse sujeito pragmático pede espaço e aquilo que ele não atinge no virtual, demanda no real. No funcionamento social contemporâneo, a tecnologia das relações não suplanta uma demanda pelo corpo presente. Por isso, não basta ser famoso no espaço da internet. É preciso o encontro, o corpo a corpo. Esse corpo físico não se nega à própria sugestão de ser rolêzeiro, que se significa no movimento dar um rolê, rolar - e presentifica, por assim dizer, o sujeito que não se prende à tela do computador. O corpo matéria pede passagem e o sujeito circula entre o digital e o físico, sem escapar, entretanto, da rede de imaginários que o constitui enquanto sujeito rolêzeiro. Circula, mas não de qualquer forma e nem com qualquer vestimenta. E ao passar de um espaço a outro, remexe memórias que, não apenas deslocam, mas constituem o sentido dos rolês como aquilo que vem como certo modo de resistência.

Ao falar da invenção teórica do corpo no Século XX, Courtine (in CORBIN; COURTINE; VIGARELLO, 2008) atenta para o momento em que o corpo, nos fins dos 
anos 60 e durante a década de 70, é investido no contexto das lutas travadas pelos direitos das minorias: "um lugar importante de repressão, um instrumento crucial de libertação, a promessa de uma revolução. "(Idem, p.9). Assim, o corpo passa a figurar como objeto de resistência de classes marginalizadas. Resistir é colocar-se à frente com seu corpo. É essa "mutação do olhar", o modo de considerar o corpo a partir de então, que ecoa numa memória de movimentos, de lutas, de resistências, quando colocamos em discussão fenômenos como este que estamos analisando. Não há como também não considerar que o ano em que se sucederam os rolêzinhos, com maior intensidade inclusive na mídia, trouxe antes deles as conhecidas "Jornadas de Junho", manifestações de rua que declaravam resistência ao aumento de tarifas públicas no Brasil.

Não se trata, obviamente, da mesma coisa e nem é esse especificamente o foco de nosso estudo. Mas não podemos deixar de salientar que, do mesmo modo que em junho daquele ano, ao tratar do assunto, por um trabalho da mídia, "manifestante" deslizou para "vândalos", também o sentido de rolêzinho deslizou, mais tarde, para "arrastão" e "vandalismo".

A memória do "corpos-juntos", da "multidão-caminhando-no-mesmo-sentido", não deixou de produzir seus efeitos e, como diz Henry (1997), se não há fato ou evento histórico que não reclame sentidos, esses já chegaram pré-fabricados, colocando em pauta o jogo político dos lugares sociais, a partir dos comentários que se sucederam.

Se os rolêzinhos são, para nós, um sintoma de como as relações de consumo se colocam como estruturantes da forma sujeito contemporânea, também apontam para aquilo que o corpo tem de história, e que funciona na incompletude desse sujeito determinado pela ideologia e pelo inconsciente.

\section{Referências}

ACHARD, Pierre. Memória e produção discursiva do sentido. In: ACHARD, Pierre et al. Papel da memória. Trad. José Horta Nunes. Campinas: Pontes, 1999.

BALDINI, Lauro. Cidade e sujeito na rede. In ORLANDI. E. P. (Org). Discurso, espaço, memória: caminhos da identidade no sul de Minas. Campinas: Editora RG, 2011.

CORBIN, Alain; COURTINE, Jean-Jacques; VIGARELLO, Georges. História do corpo: as mutações do olhar: o século XX. Vol. 3. Tradução de Ephraim Ferreira Alves. Petrópolis, RJ: Vozes, 2008.

HENRY, Paul. A história não existe? In ORLANDI, Eni P. (Org.) Gestos de leitura: da história no discurso. 2 ed. Campinas, SP, Editora da Unicamp. 1997. p. 29-53

ORLANDI, Eni P. Discurso, imaginário social e conhecimento. Revista Em Aberto. Ano 14, n. 61, p. 52-59. Brasília, jan/mar 1994. 
Pontes, 2001.

Discurso e Texto: formulação e circulação dos sentidos. Campinas, SP:

À flor da pele: indivíduo e sociedade. In MARIANI, Bethania (Org.) A escrita e os escritos: reflexões em análise do discurso e psicanálise. São Carlos: Claraluz, 2006. P. 21-30

Discurso em análise: sujeito, sentido, ideologia. Campinas: Pontes, 2012.

PÊCHEUX, Michel. Ler o arquivo hoje. In: ORLANDI, Eni P. (Org.) Gestos de leitura: da história no discurso. 2 ed. Campinas: Editora da Unicamp, 1997.

, Papel da Memória. In: ACHARD, Pierre et al. Papel da memória. Trad. José Horta Nunes. Campinas: Pontes, 1999.

\section{SITES}

http://tvuol.uol.com.br/video/voce-conhece-as-rolezeiras-descubra-quem-sao-e-o-quepensam-essas-meninas-04024E9B3162CCC14326/. Acessado em 10 de fevereiro de 2016.

https://www.youtube.com/watch?v=JMp-h54fweU. Acessado em 10 de fevereiro de 2016.

Data de Recebimento: 27/07/2016

Data de Aprovação: 18/10/2016 


\section{Para citar essa obra:}

CARROZZA, G. ALVARENGA, C. C. Consumo, espaço e identificação: o sujeito rolêzeiro na rede de sentidos. In: RUA [online]. nº. 22. Volume 2, p. 397 - 406 - ISSN 1413-2109/2179-9911 - Novembro/2016. Consultada no Portal Labeurb - Revista do Laboratório de Estudos Urbanos do Núcleo de Desenvolvimento da Criatividade. http://www.labeurb.unicamp.br/rua/

Capa: Figura do artigo

\section{Laboratório de Estudos Urbanos - LABEURB}

Núcleo de Desenvolvimento da Criatividade - NUDECRI

\section{Universidade Estadual de Campinas - UNICAMP}

http://www.labeurb.unicamp.br/

\section{Endereço:}

LABEURB - LABORATÓRIO DE ESTUDOS URBANOS

UNICAMP/COCEN / NUDECRI

CAIXA POSTAL 6166

Campinas/SP - Brasil

CEP 13083-892

Fone/ Fax: (19) 3521-7900

Contato: http://www.labeurb.unicamp.br/contato 